\title{
An accurate REDD+ reference level for Terai Arc Landscape, Nepal using LiDAR assisted Multi-source Programme (LAMP)
}

A. R. Joshi ${ }^{1}$, K. Tegel ${ }^{2}$, U. Manandhar ${ }^{3}$, N. Aguilar-Amuchastegui ${ }^{4}$,E. Dinerstein ${ }^{5}$, A. Eivazi ${ }^{2}$ L. Gamble ${ }^{4}$, B. Gautam ${ }^{2}$, K. Gunia ${ }^{2}$, M. Gunia ${ }^{2}$, D. Hall ${ }^{4}$, J. Hämäläinen ${ }^{2}$,

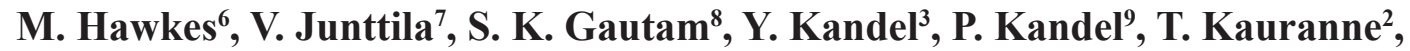
A. Kolesnikov ${ }^{2}$, P. Latva-Käyrä² ${ }^{2}$ S. Lohani ${ }^{4}$, S. M. Nepal ${ }^{3}$, J. Niles ${ }^{10}$, J. Peuhkurinen ${ }^{2}$, G. Powell ${ }^{4}$, P. Rana ${ }^{2}$, T. Suihkonen ${ }^{2}$ and G. J. Thapa ${ }^{3}$

In preparation for participation in funding mechanisms established under the United Nations' framework for reducing emissions from deforestation and forest degradation (REDD+), the Government of Nepal has developed a sub-national reference level $(R L)$ for the 12 districts of Terai Arc Landscape (TAL) in partnership with the WWF-Nepal, WWF-US and Arbonaut Ltd., Finland. The reference level was established using LiDAR-Assisted Multisource Programme (LAMP), an innovative effort that utilizes existing national forest and survey data, field sampling, satellite imagery, and airborne LiDAR data to measure deforestation and forest degradation, regrowth and maintenance of forests, and the resulting emissions and sequestration of $\mathrm{CO}_{2}$ in the project districts for the period 1999-2011. This effort was designed to create a sub-national $R L$ that meets the highest international standards for integrity and transparency and followed closely the guidelines of the Methodological Framework (MF) defined by the Forest Carbon Partnership Facility (FCPF) at the World Bank and Guidelines defined by Intergovernmental Panel on Climate Change (IPCC). The present analysis shows that during the 12-year period between 1999 and 2011 a net total of 52,245,991 tons $\mathrm{CO}_{2}\left(\mathrm{tCO}_{2} \mathrm{e}\right)$ was emitted from the forest sector in the TAL, an average emission of $4,353,833$ tons $\mathrm{CO}_{2}$ e per year. The results presented here reflect the first iteration of the TAL RL and a major milestone in an on-going process that will further refine and improve the RL in the months ahead based on external review and input and additional field verification and data analysis.

Key words: REDD+, sub national, reference level, LiDAR, satellite data, field plots, LAMP, carbon, Nepal

$\mathrm{G}$ reenhouse gas (GHG) emissions from tropical deforestation and forest degradation contribute about $15-20 \%$ of total annual global GHG emissions, making them the second largest source globally (IPCC, 2013). To reduce especially $\mathrm{CO}_{2}$ (carbon dioxide) emissions from the forestry sector, the United Nations has established a programme that would provide payments for the reduction of emissions from deforestation and forest degradation (REDD+). REDD+ will provide countries performancebased payments for reduced emission rates tied to

an agreed reference level or baseline. The baseline reference level (RL) is the estimated amount of $\mathrm{CO}_{2}$ that is emitted and sequestered from the forest sector in a business-as-usual (BAU) scenario. The BAU scenario for emissions must be based on historical emissions and, in a limited number of cases, adjustments based on national circumstances. The guidance on modalities relating to development of reference levels (RLs) was provided in late 2011 by the UNFCCC. The UNFCCC explicitly stated that RLs would be the essential metric to assess performance and must

Conservation Biology Program, University of Minnesota, Minneapolis, USA, Email: joshi002@umn.edu

2 Arbonaut Ltd., Joensuu, Finland

3 World Wildlife Fund (WWF), Kathmandu, Nepal

World Wildlife Fund (WWF), Washington DC, USA

${ }^{5}$ Biodiversity and Wildlife Solutions Program, RESOLVE, Washington DC, USA

Forest Resource Assessment (FRA) Nepal Project, Kathmandu, Nepal

7 Lappeenranta University of Technology (LUT), Lappeenranta, Finland

${ }^{8}$ Department of Forest Research and Survey (DFRS), Kathmandu, Nepal

9 Department of Soil Conservation and Watershed Management (DSCWM), Kathmandu, Nepal

${ }^{10}$ University of California, San Diego, USA 
be reported in tons of carbon dioxide equivalent per year $\left(\mathrm{tCO}_{2} \mathrm{e} /\right.$ year).The process to develop a RL must be transparent, complete, consistent, and verifiable at national and sub-national scales (UNFCCC, 2011). The Forest Carbon Partnership Facility (FCPF) at the World Bank recently published a Methodological Framework (MF) to guide development of emission reduction programmes. Submitted RLs should be based on Intergovernmental Panel on Climate Change (IPCC) Good Practice Guidelines for National Greenhouse Gas Inventories (IPCC, 2006), which provide further guidelines for building countrylevel REDD+ readiness activities to gain credits for Emission Reductions (FCPF, 2013).

At its core, the reference level (RL) is calculated as Emission Factors multiplied by the Activity Datafor change in forest cover (deforestation, degradation, regrowth, and enhancement). Therefore to generate a RL we need to know 1) emission factors which is amount of carbon emitted or sequestered when the forest class changes from one activity to another. To calculate emission factor, we first need to know the amount of biomass in each forest type and structural class; 2 ) activity data which is how muchland changed from one structural class to another in a given period of time.

Combining remotely sensed data with a forest resource inventory data provides practical means to generate emission factors (GOFC-GOLD, 2010). However, no current remote sensing system directly measures forest biomass and sequestered carbon. Hence, in a joint effort, Arbonaut, the Forest Resource Assessment Nepal project and WWF carried out a landscape-level LiDAR-assisted forest biomass inventory in the Terai and Siwaliks region of Nepal in 2011.

In recent years, the high potential of airborne LiDAR for REDD-related biomass inventories has been well demonstrated (Asner et al., 2009; Gautam et al., 2010; Asner et al.,2012; Asner et al., 2013; Gautam et al., 2013; Peuhkurinen et al., 2013). The LiDAR-Assisted Multi-source Programme (LAMP) is a feasible approach to carbon accounting that requires LiDAR coverage of only a small percentage of the area of interest (Sah et al., 2012; Gautam et al., 2010). These data can be combined with data from field plots and satellite imagery to develop an aboveground carbon density map over the entire study area. The resulting accurate, high-resolution forest carbon baseline together with activity data helps to derive RLs and supports forest carbon monitoring activities (Meridian Institute, 2011).

Changes in forest conditions and/or land use in the past 10 years are necessary to generate Activity Data, the second component used to calculate a RL. Nepal, like many developing countries, lacks regular forest mapping and monitoring required for this process. In absence of these data, remote sensing tools analyzing satellite imagery have been used to generate historic forest change data retro-prospectively (Morton et al., 2011; Monteiro and Souza Jr., 2012; Souza Jr. and Siqueira, 2013). Thereby yielding the activity data required to develop the RL.

Nepal is one of the first countries to receive REDD+ funds from the FCPF to achieve REDD+ readiness and has now completed the preparation of the final REDD+ readiness document including the development of this sub-national baseline RL.The purpose of this paper is to summarizethe process being utilized for this sub-national REDD+ programme in the TAL to develop RL in accordance with the IPCC GPG and the FCPF's Methodological Framework. The process is documented inmore detail in Nepal's Emission Reductions -Program Idea Note to FCPF Carbon Fund (REDD-Cell, 2014).

\section{Materials and methods}

\section{Study Area}

The study area (Fig. 1) includes 12 districtsof the TeraiArc Landscape $\left(23,300 \mathrm{~km}^{2}\right)$, which is home for 6.7 million people. TAL is situated in the southern part of Nepal, extending from the lowlands of the Terai region up to the southern slopes of the Himalayas in Churia Hills. The altitude in the study area varies from 100 to 2,200 meters and the area is influenced by subtropical climate. About half of the study area is covered by subtropical, mainly deciduous forests. The dominating forest types are Sal (Shorea robusta), Terai mixed hardwood, Khair-Sissoo (Acacia catechu/Dalbergia sissoo) and Chirpine (Pinus roxburghii). The TAL is one of Nepal's priority landscapes, both for the conservation of its biodiversity and the protection of the ecological services it provides. 


\section{LiDAR data}

Airborne discrete-return LiDAR data were acquired in 2011 from 20 blocks of size $5 \mathrm{~km}$ by $10 \mathrm{~km}$, which covers about $5 \%$ of the study area (Fig. 1). To produce a LiDAR sample that reflects the full range of variation in biomass over the study area and that covers both common and rare forest types, different vegetation types were weighted by utilizing the forest classification of TAL (Joshi et al., 2003). Probability proportionalto-size sampling (Sarndal et al., 1992) was used to select the areas for LiDAR data collection.

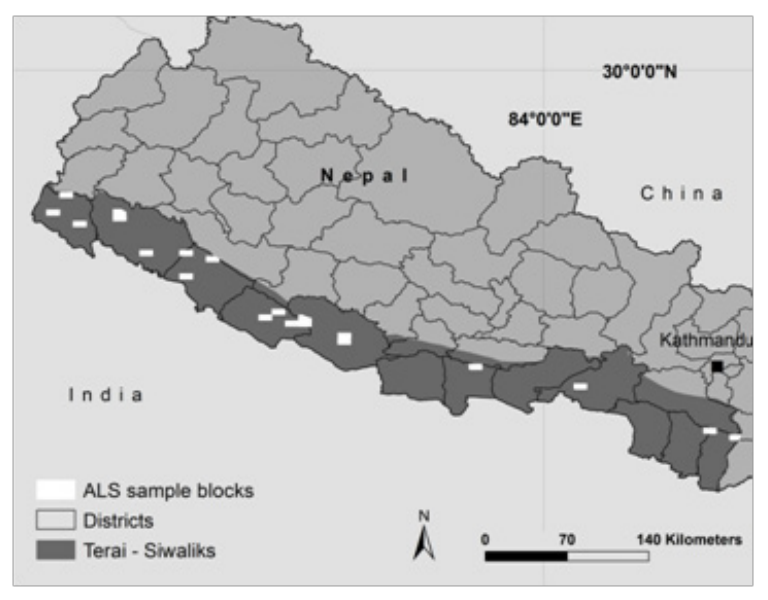

Fig. 1:Study area showing 12 districts inTerai Arc Landscape (TAL)and the LiDAR block sample

\section{Ground-truth plots for modelling above ground biomass (t/ha) and for results validation}

The ground-truth plots for modelling were sampled in systematic clusters within LiDAR blocks. Each LiDAR block contained six clusters of eight sample plots each (Fig. 2). In total, treelevel measurements (diameter, height etc.) were conducted in 2011 from 738 circular plots with fixed radius of 12.62 meters (500 sq. m.).In addition, a set of 46 field plots with a radius of 30 meters (2826 sq. m.) for independent validation were collected in 2013 from 2 LiDAR blocks. For both data sets, plot-wise aboveground biomass ( $t /$ ha) was computed using species group-specific volume equations published by Sharma and Pukkala (1990).

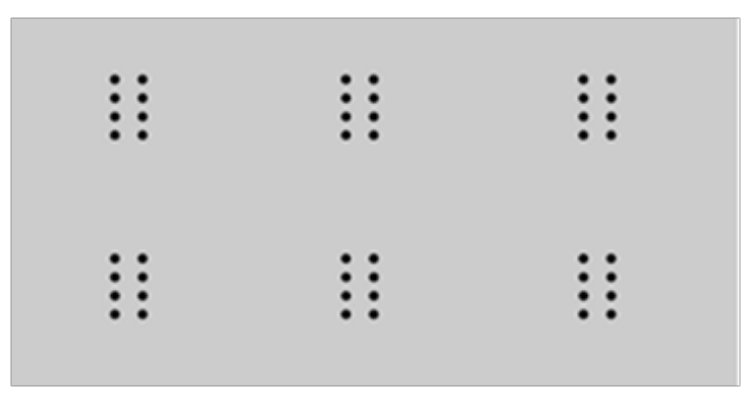

Fig. 2: LiDAR block with six clusters of eight field plots each

\section{Satellite data}

Medium-resolution, geo referenced Land sat satellite images (USGS, 2012) for the entire study area from 1999, 2002, 2006, 2009 and 2011 were obtained from the USGS website (http://glovis. usgs.gov).

\section{Forest cover map}

The Government of Nepal (1998) Topographic and Land cover, Land Use maps with forest and non-forest classes were used as the forest mask for each time period between 1999 and 2011.

\section{Forest classification map}

The carbon stocks in the forest vary by both forest types and forest structures. The forest type boundaries were obtained from afield-verified forest classification of Terai Arc Landscape (TAL) by Joshi et al. (2003). The original classes were regrouped into 4 major forest classes: Sal forest ( $S$. robusta), Sal dominant mixed forest, Riverine forest, and other forest ("other mixed forest"). The accuracy assessment for the four major forest classes were recomputed with the field data collected from 2002 (Olofsson et al., 2013). It was assumed that forest types are not likely to change from one type to another in 10-20 years but forest condition within each forest type (intact, degraded, and deforested) may change due to human activity (activity data).

\section{Remote sensing validation data}

The Rapid Eye imagery from 2010 was used to validate forest cover classification and the MDA Information Services LLC Persistent Change Monitoring (PCM) global dataset to verify areas of change for 2011. 


\section{Forest structural classification}

Spectral Matrix Analysis (SMA) uses linear mixture models to provide physical representations of reflectance in satellite imagery from different land surfaces as continuous fields of spectral endmember abundance (Small, 2004; Souza Jr. et al., 2005). We used Img Tools software developed for identifying forest disturbance in Brazilian Amazon forests (Souza Jr. et al., 2005; Souza Jr. and Siqueira, 2013) to classify forest into structural classes. ImgTools has been successfully used for studying historical emissions from deforestation and forest degradation in Brazil (Morton et al., 2011; Monteiro and Souza Jr., 2012).

The pixel reflectance values in satellite imagery are often a mixture coming from more than one source. For example, one $30 \mathrm{~m}$ x $30 \mathrm{~m}$ Landsat pixel might represent reflectance from both vegetation and bare soil. ImgTools decomposes this spectral mixture into pure members of each signature known as the "endmembers" using built-in generic spectral library for Landsat imagery and also generates a composite index called Normalized Difference Fractional Index (NDFI). We looked at the spectral curves of the green (photosynthesis) vegetation (GV), Nonphotosynthesis (senescent/dead) vegetation (NPV), bare Soil (S), and shade normalized GV (GVs) to find natural breaks, and to build threshold values to identify intact, degraded and nonforest areas. These threshold values were used to develop a decision tree for classifying forest into three structural classes, intact, degraded and nonforest and generating forest structural map.

\section{Generating a forest types and conditions map}

The four forest types in forest classification map were overlaid on the forest structural map to generate forest types and conditions classes for each time period.

\section{LiDAR-to-AGB model}

A Sparse Bayesian method was used to develop a regression model to estimate above ground biomass ( $\mathrm{t} / \mathrm{ha}$ ). The model utilizes the relationship between LiDAR metrics (Tables 1 and 2) and field measured AGB (t/ha) (Junttila et al., 2008; Junttila et al., 2010) and achieved a strong coefficient of determination $\left(\mathrm{R}^{2}\right)$ of 0.9 while no significant bias was present, as validated against the independent field data. Full validation results are shown in figure 3 and table 3.

Table 1: Final selection of LiDAR variables for predicting above-ground biomass (t/ha) using Sparse Bayesian regression

\begin{tabular}{ll}
\hline $\begin{array}{l}\text { LiDAR } \\
\text { metrics }\end{array}$ & \multicolumn{1}{c}{ Description } \\
\hline $\mathrm{L}_{1}$ & $\begin{array}{l}\text { Height of the } 10 \% \text { percentile for first pulse } \\
\text { heights }\end{array}$ \\
$\mathrm{L}_{8}$ & $\begin{array}{l}\text { Height of the } 80 \% \text { percentile for first pulse } \\
\text { heights }\end{array}$ \\
$\mathrm{L}_{11}$ & $\begin{array}{l}\text { Ratio of last pulse points with height } \\
\text { lower than } 1.5 \mathrm{~m} \text { and the total number of } \\
\text { last pulse returns }\end{array}$ \\
$\mathrm{L}_{15} \quad \begin{array}{l}\text { Ratio of last pulse points with height } \\
\text { lower than } 13.5 \mathrm{~m} \text { and the total number of } \\
\text { last pulse returns }\end{array}$ \\
$\mathrm{L}_{16} \quad \begin{array}{l}\text { Ratio of last pulse points with height } \\
\text { lower than } 16.5 \mathrm{~m} \text { and the total number of } \\
\text { last pulse returns }\end{array}$ \\
$\mathrm{L}_{27}$ & $\begin{array}{l}\text { Mean of the largest three heights within } \\
\text { first pulse returns }\end{array}$ \\
$\mathrm{L}_{29}$ & $\begin{array}{l}\text { The ratio of first pulse points under } 5 \mathrm{~m} \\
\text { and all first pulse returns }\end{array}$ \\
\hline
\end{tabular}

Table 2: Coefficients of the linear model for predicting above-ground biomass ( $t / \mathrm{ha}$ ) from LiDAR variables

\begin{tabular}{lr}
\hline \multicolumn{1}{c}{ Model parameter } & Coefficient \\
\hline Intercept & 288.936 \\
$\mathrm{~L}_{1}$ & 8.808 \\
$\mathrm{~L}_{8}$ & 2.157 \\
$\mathrm{~L}_{11}$ & 149.906 \\
$\mathrm{~L}_{15}$ & -237.074 \\
$\mathrm{~L}_{16}$ & -116.254 \\
$\mathrm{~L}_{27}$ & 1.802 \\
$\mathrm{~L}_{29}$ & -105.539 \\
\hline
\end{tabular}




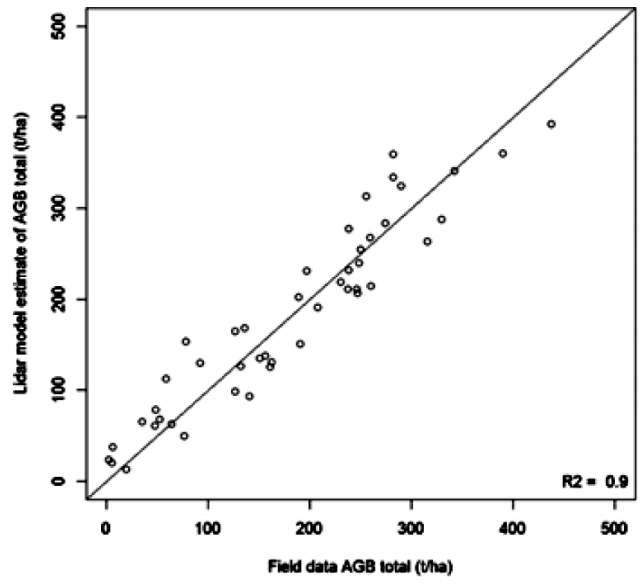

Fig. 3: Validation of LiDAR model estimates ( $t / h a)$ against independent field data with 30 meters radius

Table 3: Statistics for the LiDAR estimates of above-ground biomass $(t / h a)$ validated against independent field data with $\mathbf{3 0}$ meters radius

\begin{tabular}{lr}
\hline Standard deviation of estimates & 103.1 \\
Standard deviation of reference plots & 108.5 \\
Mean of reference plots & 180.4 \\
Mean of estimates & 183.3 \\
RMSE & 34.5 \\
Relative RMSE (\%) & 19.1 \\
Bias & 2.9 \\
Relative bias (\%) & 1.6 \\
$\mathrm{R}^{2}$ & 0.9 \\
\hline
\end{tabular}

LiDAR-Assisted Multi-source Programme (LAMP) Estimation for calculating above ground biomass $(t / h a)$ for different forest types and conditions

The forest types and conditions map from 2011 was overlaid on all LiDAR blocks. In the next step, nearly 1,000 forest type and conditionspecific "surrogate plots" (simulated field plots) of 1-hectare size were randomly generated inside the forest mask within LiDAR blocks, and above ground biomass was predicted for them using regression model based on LiDAR features. If a surrogate plot has multiple forest type and condition classes, then weighted average mean for only the dominant class was recorded (Table 4). The mean biomass values calculated from LiDAR area for each forest condition bytype were applied for respective classes in the classified satellite imagery, to map biomass over the whole study area.
Table 4: Forest type and condition-specific statistics for above-ground biomass (t/ha) from surrogate plots of size 1 ha

\begin{tabular}{lrrrrr}
\hline \multicolumn{1}{c}{ Class } & $\begin{array}{r}\text { No. of } \\
\text { Surro } \\
\text { gates }\end{array}$ & Mean & Min & Max & StD \\
\hline 1. Sal intact & 988 & 235.6 & 20.4 & 509.5 & 84.1 \\
2. Sal degraded & 969 & 173.2 & 0.0 & 425.3 & 72.9 \\
3. Salmix intact & 966 & 183.2 & 0.0 & 556.9 & 84.7 \\
4. Salmix degraded & 946 & 146.4 & 0.0 & 539.6 & 106.2 \\
5. Othermix intact & 985 & 186.1 & 5.5 & 479.5 & 94.0 \\
6. Othermix degraded & 943 & 143.2 & 0.4 & 461.6 & 86.8 \\
7. Riverine intact & 934 & 171.1 & 0.0 & 405.5 & 46.8 \\
8. Riverine degraded & 979 & 99.4 & 0.0 & 505.6 & 57.9 \\
\hline
\end{tabular}

Time series analysis - generation of activity data

To delineate areas of deforestation, degradation and regeneration, we completed a time-series analysis of forest change for the project districts on TAL for four time periods, 1999-2002, 20022006, 2006-2009 and 2009-2011, using the classified satellite images (structural classes) in ERDAS Imagine to produce a change matrix at pixel level. This resulted in a 25-class matrix for the first set of image pairs, time periods $\mathrm{T} 1$ and T2. Any forested area under the cloud and cloud shadow (cloud/shadow class) was considered as unchanged between the two periods for the purpose of this study. Likewise areas remaining in same classes between the two periods were also considered unchanged. The change classes derived from the change matrix are listed below (Table 5) as Deforestation 1-3, Degradation, and Regeneration 1-3.

Table 5: New classes derived from the change matrix

\begin{tabular}{ll}
\hline \multicolumn{1}{c}{ Change Matrix } & \multicolumn{1}{c}{ Change Class } \\
\hline Intact forest to non-forest & Deforestation 1 \\
Intact forest to degraded forest & Degradation \\
Degraded forest to non-forest & Deforestation 2
\end{tabular}

Non-forest to dense regenerating Regeneration 1 forest

Non-forest to sparse regenerating Regeneration 2 forest

Degraded forest to regenerating Regeneration 3 forest

Regeneration forest to non-forest Deforestation 3 
For the subsequent time-series analysis the base classified image for that series (time T1) was adjusted to reflect changes in the previous time period; for example change classes derived in table 5 as a change between $\mathrm{T} 1$ and $\mathrm{T} 2$ were delineated and re-coded in the T2 scene. All three types of deforestation were merged into one deforestation class because they represent areas going from forest to non-forest. Therefore, each base image potentially has nine classes: Intact Forest, Degraded Forest, Non-forest, Water, Cloud/Shadow, Deforestation, and Regeneration $1-3$. The change analysis between 2002 and 2006 resulted in a 45-class change matrix with nine classes (described above) representing actual change in forest conditions. These nine change classes were adjusted in the base image (2006) for analyzing time series 2006 to 2009 . The same process was repeated for 2009 to 2011 series. The areas under each activity (Deforestation 1-3, Degradation, and Regeneration 1-3) for each time series analysis were used to generate activity data. Activities Regeneration 1-3 were combined to a single Regeneration activity because all these activities were differentiated only based on activities in the previous time period that resulted in regeneration in the current period, thus their growth rates and mean carbon content are assumed to be same.

\section{Calculation of emission factors}

The emission factors for each forest type and condition were calculated multiplying the AGB (t/ha) by $47 \%$ (Table 6 ), as consistent with GPG (Chapter 4, Table 4.4, IPCC, 2006). When the forest changed from intact or degraded forest to deforestation all carbon was assumed to be released. But when forest wentfrom intact to degraded the difference in the mean carbon contents between intact and degraded forest was assumed to be emitted. Emissions factors were derived by calculating the difference between the carbon and $\mathrm{CO}_{2} \mathrm{e}$ values in table 6 to reflect the loss of carbon or amount of emissions when land area containing various forest types transitions from one structure to another. For the emission factors for regeneration forest changing to deforestation or degradation, and sequestrations due to regeneration we used the IPCC default value of 6.0 tons of dry biomass per hectare per year,which equals to $2.82 \mathrm{tC} / \mathrm{ha} / \mathrm{yr}$ (IPCC, 2006, Volume 4, Table 4.9). The below ground biomass was estimated as $20 \%$ of above ground biomass (IPCC, 2006).
Table 6: The mean Emission Factors and $\mathrm{CO}_{2} \mathrm{e}$ values for different forest types and conditions

\begin{tabular}{lrr}
\hline \multicolumn{1}{c}{$\begin{array}{c}\text { Forest type and } \\
\text { Condition }\end{array}$} & \multicolumn{2}{c}{$\mathbf{C}$ and $\mathbf{C O}_{\mathbf{2}} \mathbf{e}$ Values } \\
\cline { 2 - 3 } & tC/ha & tCO_e/ha \\
\hline Sal intact & 110.7 & 406.0 \\
Sal degraded & 81.4 & 298.5 \\
Salmixed intact & 86.1 & 315.7 \\
Salmix degraded & 68.8 & 252.3 \\
Othermix intact & 87.4 & 320.7 \\
Othermix degraded & 67.3 & 246.8 \\
Riverine intact & 80.4 & 294.9 \\
Riverine degraded & 46.7 & 171.3 \\
\hline
\end{tabular}

\section{Generating Reference Level (RL)}

The RL is generated by multiplying areas changed under each activity by the appropriate emission factor.

$$
R L=\text { Activity data } \times \text { Emission factors }
$$

The amount of $\mathrm{CO}_{2}$ released due to loss of forest carbon resulting from deforestation and degradation is termed as gross emissions while intake of $\mathrm{CO}_{2}$ by growing plants during forest regeneration is called sequestration. Therefore, net carbon loss is equal to gross emissions minus sequestrations. The reference level (RL) for TAL is based on net carbon accounting process.

Following formula was used to calculate RL for each forest type in TAL.

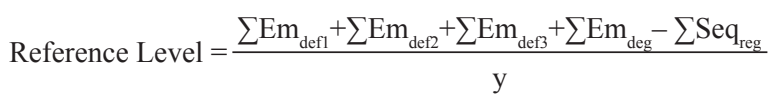

Where,

$\sum \mathrm{Em}_{\text {def } 1}$ is the sum of emissions from deforestation of intact forest over "y" years,

$\sum \mathrm{Em}_{\text {def } 2}$ is the sum of emissions from deforestation of degraded forest over "y" years,

$\sum \mathrm{Em}_{\text {def3 }}$ is the sum of emissions from deforestation of regenerated forest over " $y$ " years,

$\sum \mathrm{Em}_{\mathrm{deg}}$ is the sum of emissions from degradation over " $y$ " years,

$\sum \mathrm{Seq}_{\mathrm{reg}}$ is the sum of sequestrations from regeneration over " $y$ " years.

\section{Results and discussion}

\section{Reference Level (RL)}

The RL analysis shows that during the 12-year period between 1999 and 2011 a net total of $52,245,991$ tons $\mathrm{CO}_{2}\left(\mathrm{tCO}_{2} \mathrm{e}\right)$ was emitted from 
the forest sector in the TAL, an average emission of $4,353,833$ tons $\mathrm{CO}_{2}$ e per year (Table 7). In the period 2006-2011, emissions averaged 6,879,686 $\mathrm{tCO}_{2} \mathrm{e}$ per year, an increase of $58 \%$ over the 12-year average, and in the period 2009-2011, emissions increased even more dramatically, averaging $11,412,396 \mathrm{tCO}_{2} \mathrm{e}$ per year or $162 \%$ higher than the 12-year average (Fig. 4).

Table 7: Forest-related $\mathrm{CO}_{2}$ emissions in TAL between 1999 and 2011

\begin{tabular}{|c|c|c|c|}
\hline \multirow[b]{2}{*}{ Period } & \multicolumn{3}{|c|}{$\mathrm{CO}_{2}$ Emissions $\left(\mathrm{tCO}_{2} \mathrm{e}\right)$} \\
\hline & $\begin{array}{l}\text { Above- } \\
\text { ground }\end{array}$ & $\begin{array}{l}\text { Below- } \\
\text { ground }\end{array}$ & Total \\
\hline 1999-2002 & $13,136,430$ & $2,627,286$ & $15,763,716$ \\
\hline 2002-2006 & $1,736,537$ & 347,307 & $2,083,845$ \\
\hline 2006-2009 & $9,644,698$ & $1,928,940$ & $11,573,637$ \\
\hline 2009-2011 & $19,020,661$ & $3,804,132$ & $22,824,793$ \\
\hline Total 12-yr & $43,538,325$ & $8,707,665$ & $52,245,991$ \\
\hline $\begin{array}{l}\text { Average } \\
\text { annual }\end{array}$ & $3,628,193.79$ & 725,639 & $4,353,833$ \\
\hline
\end{tabular}

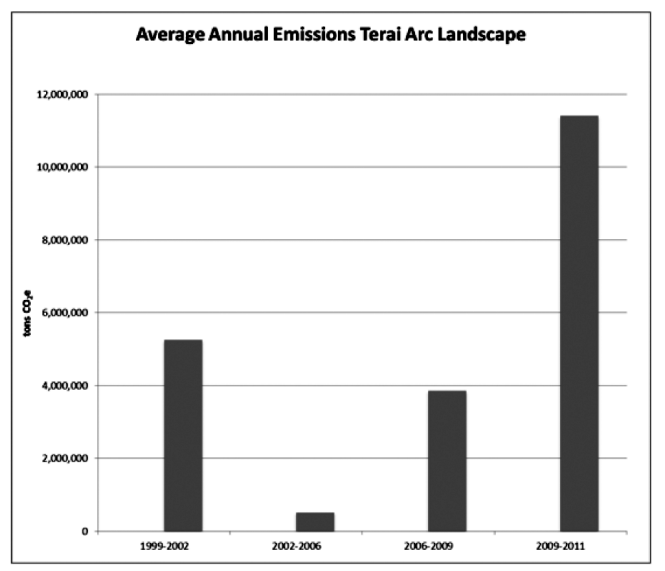

Fig. 4: Average annual net $\mathrm{CO}_{2}$ emissions $\left(\mathrm{tCO}_{2} \mathrm{e}\right)$ in TAL between 1999 and 2011

Accuracy assessments, errors and uncertainties

Accuracy assessment for emission factors
A non-stratified regression model was used to generate LiDAR-based biomass estimates for all forest classes. Thus, the within-class uncertainty in predictions was considered by calculating the mean error of an estimator ME $(\theta)$ for each class. The $\operatorname{ME}(\theta)$ assesses the quality of an estimator in terms of its variation and unbiasness (Moore and McCabe, 2001). It is calculated as the root of the sum of the variance and the squared bias of the estimator:

$$
\operatorname{ME}(\theta)=\sqrt{ }\left(\operatorname{var}(\theta)+\operatorname{bias}(\theta)^{2}\right) \quad \text { Eq.1 }
$$

\section{Spatial scaling of error measures}

Scaling of the mean error by size of estimation area decreases the error associated with corresponding average AGB ( $t / h a)$. In order to reveal maximum level of error for each forest type and condition class, the mean error was spatially scaled up to the area thateach class had on the LiDAR blocks (Table 8). Bias was calculated from 738 field verified plots for classes intact and degraded and assumed to be close to each other between the four forest types.

\section{Monte Carlo analysis of the Emission Factors prediction errors}

We ran a Monte Carlo analysis for accuracy of Emission Factor estimation. The estimation process starts from the field measurements and then proceeds on to the LiDAR model that is built upon them. For the combined error of both field measurements and LiDAR model construction we can use cross-validation. By cross-validation, we obtain an empirical distribution of the combined LiDAR model, plot measurement and field sampling error that can be used as the starting point of the Monte Carlo analysis for Emission Factor errors. Thisprio rerror distribution was estimated

Table 8: Confidence intervals (CI) and Mean error (ME) of LiDAR-estimated mean AGB(t/ha) for each forest type and condition class on the minimum area of each class on $5 \mathrm{~km}$ x $10 \mathrm{~km}$ LiDAR blocks

\begin{tabular}{lrrrrr}
\hline \multicolumn{1}{c}{ Class } & $\begin{array}{c}\text { Mean AGB, } \\
(\mathbf{t} / \mathbf{h a})\end{array}$ & $\begin{array}{c}\text { Area on } \\
\text { blocks }(\mathbf{h a})\end{array}$ & $\begin{array}{c}\text { CI, AGB } \\
(\mathbf{t} / \mathbf{h a})\end{array}$ & $\begin{array}{c}\text { CI, \% of the } \\
\text { mean AGB (t/ha) }\end{array}$ & $\begin{array}{c}\text { ME, AGB } \\
(\mathbf{t} / \mathbf{h a})\end{array}$ \\
\hline Sal intact & 235.6 & 36549 & 0.14 & 0.06 & 6.36 \\
Sal degraded & 173.2 & 1661 & 0.65 & 0.37 & 4.01 \\
Sal mixed intact & 183.2 & 11074 & 0.25 & 0.14 & 6.36 \\
Sal mixed degraded & 146.4 & 946 & 0.86 & 0.58 & 4.02 \\
Other mixed intact & 186.1 & 1129 & 0.78 & 0.42 & 6.37 \\
Other mixed degraded & 143.2 & 125 & 2.35 & 1.64 & 4.18 \\
Riverine intact & 171.1 & 478 & 1.20 & 0.70 & 6.39 \\
Riverine degraded & 99.4 & 58 & 3.46 & 3.48 & 4.37 \\
\hline
\end{tabular}


by randomly simulating 1,000 sub-samples of size 538 field plots from 738 field measurements. Each sub-sample was used to create a LiDAR-toAGB model and the results were cross-validated with the remaining 200 field plots. A new model was created each time. Thus, we obtained 1000 $\times 200$ predicted plots, from which the plot level residual distribution and mean statistics could be estimated (Fig. 5 and 6, and Table 9).

Table 9: Mean statistics for the simulated LiDAR estimates of aboveground biomass ( $t / h a)$, the results are validated with iterative cross-validation.

\begin{tabular}{lr}
\hline Standard deviation of estimates(t/ha) & 113.08 \\
Standard deviation of reference plots(t/ha) & 143.0 \\
Mean of estimates(t/ha) & 189.8 \\
Mean of reference plots(t/ha) & 188.98 \\
RMSE(t/ha) & 89.5 \\
Relative RMSE (\%) & 47.0 \\
Bias(t/ha) & 0.82 \\
Relative bias (\%) & 0.00 \\
$\mathrm{R}^{2}$ & 0.61 \\
Adj. $\mathrm{R}^{2}$ & 0.61 \\
\hline
\end{tabular}

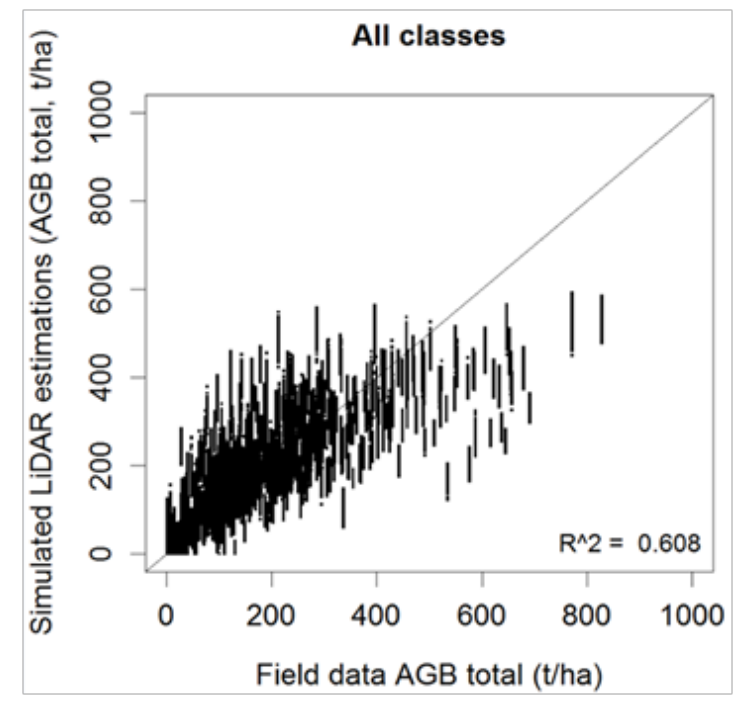

Fig. 5: Above-ground biomass ( $t / \mathrm{ha}$ ) from field data against the simulated LiDAR- estimates

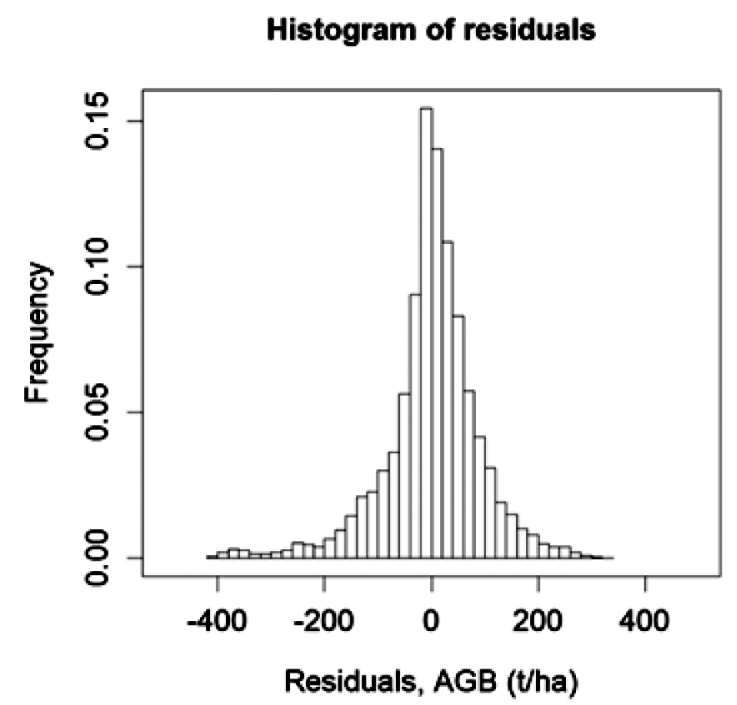

Fig. 6: Residual histogram of 1000 simulations with random training set of 538 plots

Accounting for stratification error in forest conditions

Stratification error was evaluated at regional level only. The histograms of $\mathrm{AGB}(\mathrm{t} / \mathrm{ha})$ estimations were scaled into spatially larger units in order to establish a level of spatial resolution for each forest type where the two forest condition classes, intact and degraded, could be confidently separated.

By using the scaled plot biomass values the histograms get narrower the higher the spatial scale is. The point where the histograms are not overlapping indicates a spatial scale where condition classes can be separated with confidence. At initial level of 1 hectare, the distribution of intact and degraded forest overlap heavily but cease to overlap at the level of 70 hectares and larger (Fig. 7). This means that RL results are confident at district level.

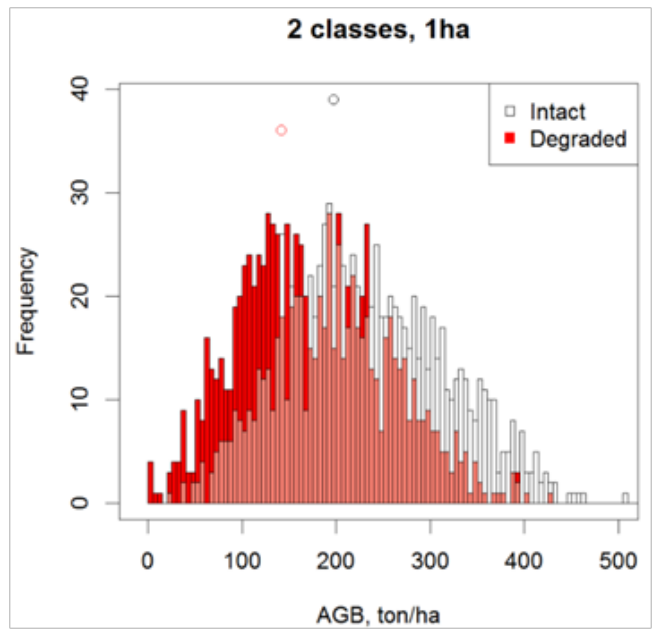




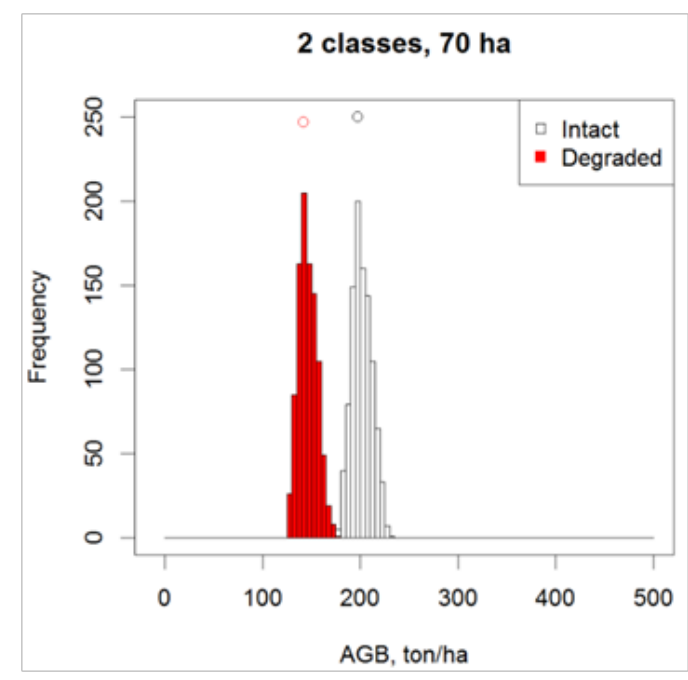

Fig. 7: Histograms of estimated AGB (t/ha) for two forest condition classes at different spatial scales. The mean biomass of each class is indicated with a circle.

\section{Accuracy Assessment of Activity Data}

The accuracy assessment of activity data is limited to the last time period (2009-2011) due to lack of affordable reference data for previous time periods. The first accuracy assessment was done by dividing the activity data classes into polygons of size 5 hectares or larger. For each activity: intact, deforested, degraded, and regenerated areas, $5 \%$ of the polygons were chosen using a random function. These polygons were visually interpreted against high-resolution satellite scenes. The accuracy assessment accounts for the proportion of each category based on mapped area as per referenced data (Olofsson et al., 2013).

\section{Conclusion}

The technical process we used in developing RL for a sub-national REDD+ program, TAL in Nepal demonstrates that historical deforestation and degradation rates can be generated retroprospectively, even in countries lacking regular forest monitoring data, to develop a creditable $\mathrm{RL}$ that is reliable and transparent. The RL for the TAL has been subjected to rigorous review and accuracy assessment, and the results are highly reliable for reporting carbon flux at scales above 70 ha. In the TAL, the RL provides highly accurate estimates of historical carbon emissions for the 12 administrative districts and will enable stakeholders in Nepal to better target interventions to curb deforestation and forest degradation. The RL provides a stark view of an alarming trend of increasing deforestation and forest degradation in the TAL, particularly in recent years, and this understanding can provide a strong foundation for mobilizing appropriate and effective actions to halt and reverse this trend and for monitoring the success of these actions in the future.

\section{References}

Asner, G. P., Mascaro, J., Anderson, C., Knapp, D. E., Martin, R. E., Kennedy-Bowdoin, T., Breugel, M. V., Davies, S., Hall, J. S., Muller-Landau, H. C., Potvin, C., Sousa, W., Wright, J. and Bermingham, E. 2013. Highfidelity national carbon mapping for resource management and REDD+. Carbon Balance and Management 8: 2.

Asner, G. P., Clark, J. K., Mascaro, J., Vaudry, R., Chadwick, K. D., Vieilledent, G., Rasamoelina, M., Balaji, A., KennedyBowdoin, T., Maatoug, L., Colgan, M. S. and Knapp, D. E. 2012. Human and environmental controls over aboveground carbon storage in Madagascar. Carbon Balance and Management 7: 2.

Asner, G. P., Hughes, R. F., Varga, T. A., Knapp, D. E. and Kennedy-Bowdoin, T. 2009. Environmental and biotic controls over aboveground biomass throughout a tropical rain forest. Ecosystems 12: 261-278.

\section{FCPF. 2013. Carbon Fund Methodological}

Framework. Forest Carbon Partnership Facility, World Bank, Washington DC, USA.

Gautam, B., Peuhkurinen, J., Kauranne, T., Gunia, K., Tegel, K., Latva-Kayra, P., Rana, P., Eivazi, A., Kolesnikov, A., Hamalainen, J., Shrestha, S. M., Gautam, S. K., Hawkes, M., Nocker, U., Joshi, A., Suihkonen, T., Kandel, P., Lohani, S., Powell, G., Dinerstein, E., Hall, D., Niles, J., Joshi, A. R., Nepal, S., Manandhar, Kandel, U. Y. and Joshi, C. 2013. "Estimation of Forest Carbon Using LiDARAssisted Multi-source Programme (LAMP) in Nepal" paper presented at International Conference on Advanced Geospatial Technologies for Sustainable Environment and Culture, Pokhara, Nepal.

Gautam, B., Tokola, T., Hamalainen, J., Gunia, M., Peuhkurinen, J., Parviainen, H. and Sah, B. 2010. "Integration of Airborne LiDAR, Satellite Imagery, and Field Measurements 
using a Two-phase Sampling Method for Forest Biomass Estimation in Tropical Forests". Paper presented in International Symposium on "Benefiting from Earth Observation", Kathmandu, Nepal.

GOFC-GOLD. 2010. A sourcebook of methods and procedures for monitoring and reporting anthropogenic greenhouse gas emissions and removals caused by deforestation, gains and losses of carbon stocks in forests remaining forests, and forestation. GOFC-GOLD Report version COP 16-1, (GOFC-GOLD Project Office, Natural Resources Canada, Alberta, Canada). http://www.gofc-gold.uni-jena.de/redd. Accessed on: $5^{\text {th }}$ March 2014.

Intergovernmental Panel on Climate Change. 2013. Climate Change 2013: The Physical Science Basis. Contribution of Working Group 1 to the Fifth Assessment Report: Chapter 6: Carbon and Other Biogeochemical Cycles. Retrieved from: http://www.ipcc. ch/report/ar5/wg1/. Accessed on: $17^{\text {th }}$ April 2014.

Intergovernmental Panel on Climate Change. 2006. Guidelines for National Greenhouse Gas Inventories. http://www.ipcc-nggip. iges.or.jp/public/2006gl/pdf/4_Volume4/ V4_04_Ch4_Forest_Land.pdf. Accessed on: $17^{\text {th }}$ April 2014.

Joshi, A. R., Shrestha, M., Smith, J. L. D. and Ahearn, S. 2003. Forest classification of Terai Arc Landscape (TAL) based on Landsat7 satellite data. A Final Report submitted WWF-US.

Junttila, V., Kauranne, T. and Leppanen, V. 2010. Estimation of forest stand parameters from airborne laser scanning using calibrated plot databases. Forest Science 56: 257-270.

Junttila, V., Maltamo, M., and Kauranne, T. 2008. Sparse Bayesian estimation of forest stand characteristics from airborne laser scanning. Forest Science 54: 543-552.

Meridian Institute. 2011. Guidelines for REDD+ Reference Levels: Principles and Recommendations. http://redd-oar.org/links/ REDD+RL.pdf. Accessed on: 10 ${ }^{\text {th }}$ April 2014.
Monteiro, A. and Souza Jr., C. 2012. Remote Monitoring for Forest Management in the Brazilian Amazon. http://cdn.intechopen. com/pdfs-wm/36968.pdf. Accessed on: $11^{\text {th }}$ April 2014.

Moore, D. S. and McCabe, G. P. 2001. Introduction to the Practice of Statistics. The third edition. W. H. Freeman and Company, New York, USA.

Morton, D. C., Sales, M. H., Souza Jr., C. M. and Griscom, B. 2013. Historic emissions from deforestation and forest degradation in MatoGrosso, Brazil: 1) source data uncertainties. Carbon Balance and Management 2011 6: 18.

Olofsson, P., Foody, G. M., Stehman, S. V. and Woodcock, C. E. 2013. Making better use of accuracy data in land change studies: Estimating accuracy and area and quantifying uncertainity using stratified estimation. Remote Sensing of Environment 129: 122131.

Peuhkurinen, J., Kauranne, T., Hamalainen, J. and Gautam, B. 2013. "Estimation of Forest Biomass Using Lidar-Assisted Multisource Programme (LAMP)". Presented at International Expert Group Meeting on Geospatial Information Systems for Multiscale Forest Biomass Assessment and Monitoring in the Hindu Kush-Himalayan Region, ICIMOD Headquarter, Kathmandu, Nepal.

REDD Forestry and Climate Change Cell, Ministry of Forests and Soil Conservation, Government of Nepal. 2014. Nepal's Emission Reductions-Program Idea Note to FCPF Carbon Fund - March 2014. Available at http://mofsc-redd.gov. np/wp-content/uploads/2014/04/er-pin1.pdf and http://report.arbonaut.com/arbo_site_ uploaded_files/pdf/er-pin1Nepal_annexes. pdf.

Sah, B. P., Hamalainen, J. M., Sah, A. K., Honji, K., Foli, E. G. and Awudi, C. 2012. The use of satellite imagery to guide field plot sampling scheme for biomass estimation in Ghanaian forest, ISPRS. Annals of Photogramatic Remote Sensing Spatial Information Science (I) 4: 221-226. doi:10.5194/ isprsannals-I-4-221-2012, 2012. 
Sharma, E. R. and Pukkala, T. 1990. Volume Equations and Biomass Prediction of Forest Trees of Nepal. Forest Survey and Statistics Division. Publication No. 47, Kathmandu, Nepal.

Small, C. 2004. The Lands at ETM+ spectral mixing space. Remote Sensing of Environment 93: $1-17$.

Souza Jr., C., Roberts, D. A. and Cochrane, M. A. 2005. Combining spectral and spatial information to map canopy damage from selective logging and forest fires. Remote Sensing of Environment 98: 329-343. Doi: 10.1016/j.rse.2005.07.013.

Souza Jr., C. and Siqueira, J. V. 2013. ImgTools: a software for optical remotely sensed data analysis. In: XVI Simpósio Brasileiro de Sensoria mento Remoto (SBSR). Foz do Iguaçu-PR.
Sarndal, C. E., Swensson, B. and Wretman, J. 1992. Model assisted survey sampling. Springer.

UNFCCC. 2011. Guidance for modalities relating to forest reference levels and forest reference emissions levels - a contribution in response to SBSTA's invitation to submit views. http://unfecc.int/resource/docs/2011/ smsn/ngo/332.pdf. Accessed on $20^{\text {th }}$ February 2014.

USGS. 2012. Landsat processing details. http://landsat.usgs.gov/Landsat_Processing _ Details.php. Accessed on $1^{\text {st }}$ August 2012. 